\title{
Conventional Brain MRI in Carbon Monoxide Poisoning
}

\author{
Ashish Khanal,' Subash Thapa, ${ }^{1}$ Pramod Kumar Chhetri ${ }^{1}$ \\ 'Department of Radiology, College of Medical Sciences, Bharatpur, Nepal.
}

\section{ABSTRACT}

Carbon monoxide poisoning is a common fatal condition which can have acute or chronic presentation with varying severity. It commonly involves globus pallidus and putamen but can involve other parts of brain. Conventional MRI using T1 weighted,T2 weighted and FLAIR sequences are helpful in determining the extent of damage to the brain. However, appropriate clinical and laboratory findings should supplement findings on imaging.

Keywords: brain; carbon monoxide; MRI; poisoning.

\section{INTRODUCTION}

Carbon monoxide poisoning (CO) is a common, inadvertent, and potentially fatal condition. It causes serious damage to brain the extent of which is directly related to the prognosis. ${ }^{1}$ Patients may present acutely or continue to be symptomatic for years with different neuropsychiatric manifestations. MRI helps to assess objective damage to the brain. We present a similar case with findings on conventional MRI.

\section{CASE REPORT}

A 24 year old male with no past illness was found unconscious in the bathroom for unknown duration. The patient had taken hot water shower run by gas geyser. He was brought to the emergency department with the Glasgow Coma Scale of 3/15. Emergency resuscitation was carried out. Vitals with oxygen saturation on pulse oxymetry and neurological examination were normal.

Initial blood gas analysis revealed respiratory acidosis with pO2 level of $39 \mathrm{mmHg}$. Complete hemogram and electrocardiogram were normal. An emergent CT of the brain was reported as normal (Fig 1.1). A provisional diagnosis of encephalopathy secondary to Carbon
Monoxide poisoning was made and he was transferred to the intensive care unit and maintained on $100 \%$ oxygen. He recovered and was extubated after 13 hours.

MRI performed $15 \mathrm{hr}$ post admission revealed symmetrical decreased signal intensity in bilateral lentiform nuclei in T1 weighted images (Fig 1.2) with increased signal intensity in T2 weighted images (Fig $1.3,1.4$ ) and FLAIR images (Fig 1.5).

\section{DISCUSSION}

Carbon monoxide is a colourless, odourless toxic gas produced during incomplete combustion of carboncontaining compounds. $\mathrm{CO}$ inhalation is the most common cause of fatal poisoning worldwide. ${ }^{2} \mathrm{CO}$ inhibits electron transport which results in disruption of mitochondrial cellular respiratory enzymes. Symptoms of poisoning are non-specific and vary from mild constitutional upset to coma, myocardial ischaemia and

Correspondence: Dr.Ashish Khanal, Department of Radiology, College of medical sciences,Bharatpur, Chitwan, Nepal. Email: ashishmaiden@gmail.com, Phone:+977-9843719255. 
death.

Magnetic resonance imaging (MRI) can reveal abnormal findings in CO-poisoned patients and is more sensitive than $\mathrm{CT}$ for their detection. ${ }^{3}$ Carbon monoxide in particular has a propensity to affect the globus pallidus which is vulnerable to generalized disease process due to rich vascular supply and high metabolic activity. ${ }^{4}$
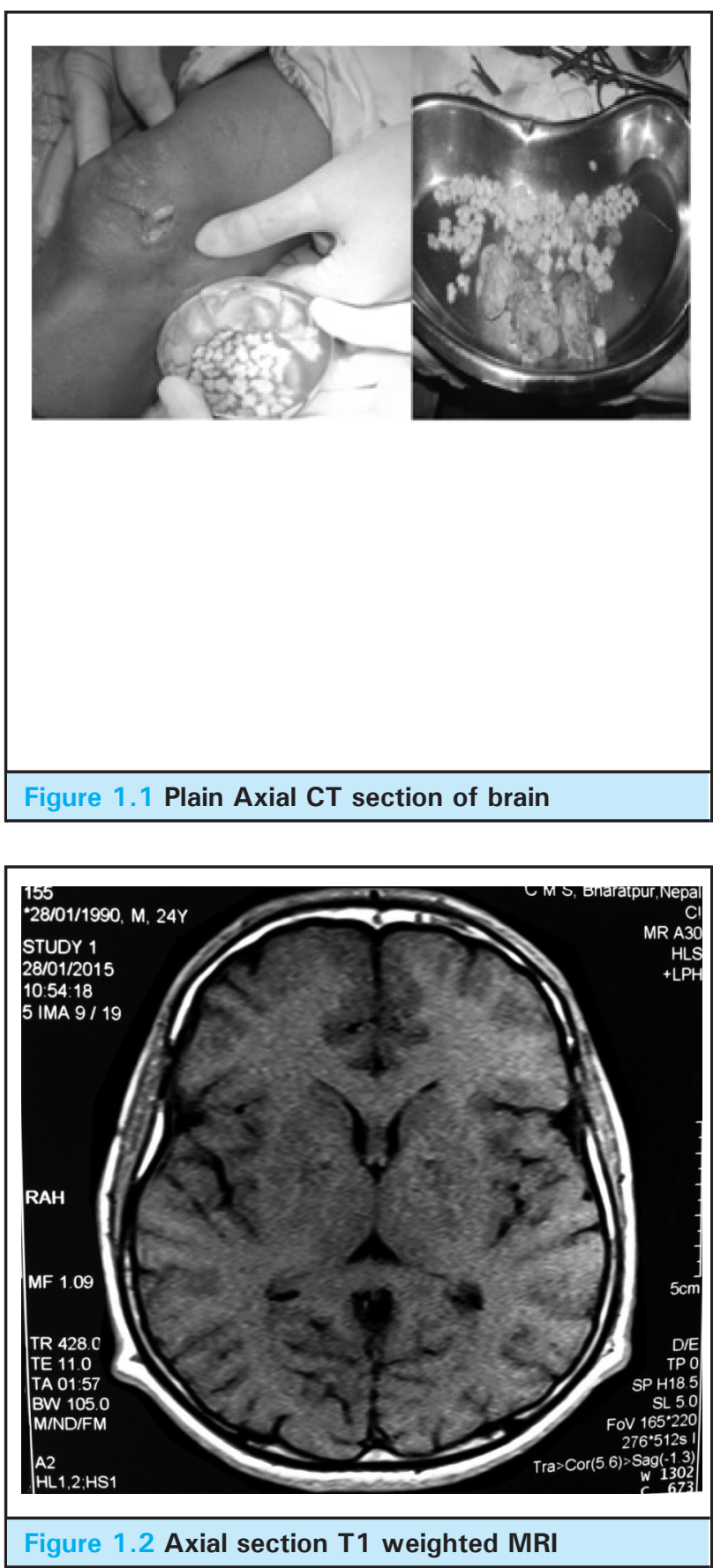

In acute $\mathrm{CO}$ poisoning, CT of the brain usually demonstrates bilateral symmetrical hypoattenuation of the globi pallidi as a result of underlying necrosis. ${ }^{5}$ This is seen on MR imaging as areas of increased signal on T2- weighted, fluid attenuated inversion recovery (FLAIR) and DW sequences as seen in our case. Contrastenhanced T1-weighted images may also demonstrate patchy or peripheral enhancement of the necrotic globus pallidus in cases of acute poisoning. Structures such as the caudate nucleus, putamen, thalamus, brainstem and cerebellum may also be involved in acute $\mathrm{CO}$ poisoning demonstrating increased signal on T2-weighted and FLAIR images with an asymmetrical distribution. Involvement of these structures may also be delayed, manifesting up to five days after the acute episode of poisoning. Cerebellar and brainstem signal abnormalities are a manifestation of more severe poisoning, as the posterior structures have a higher threshold for hypoxic injury. ${ }^{6,7}$ Diffusion MR imaging is more sensitive to the damage during the early stage of carbon monoxide poisoning. ${ }^{8}$
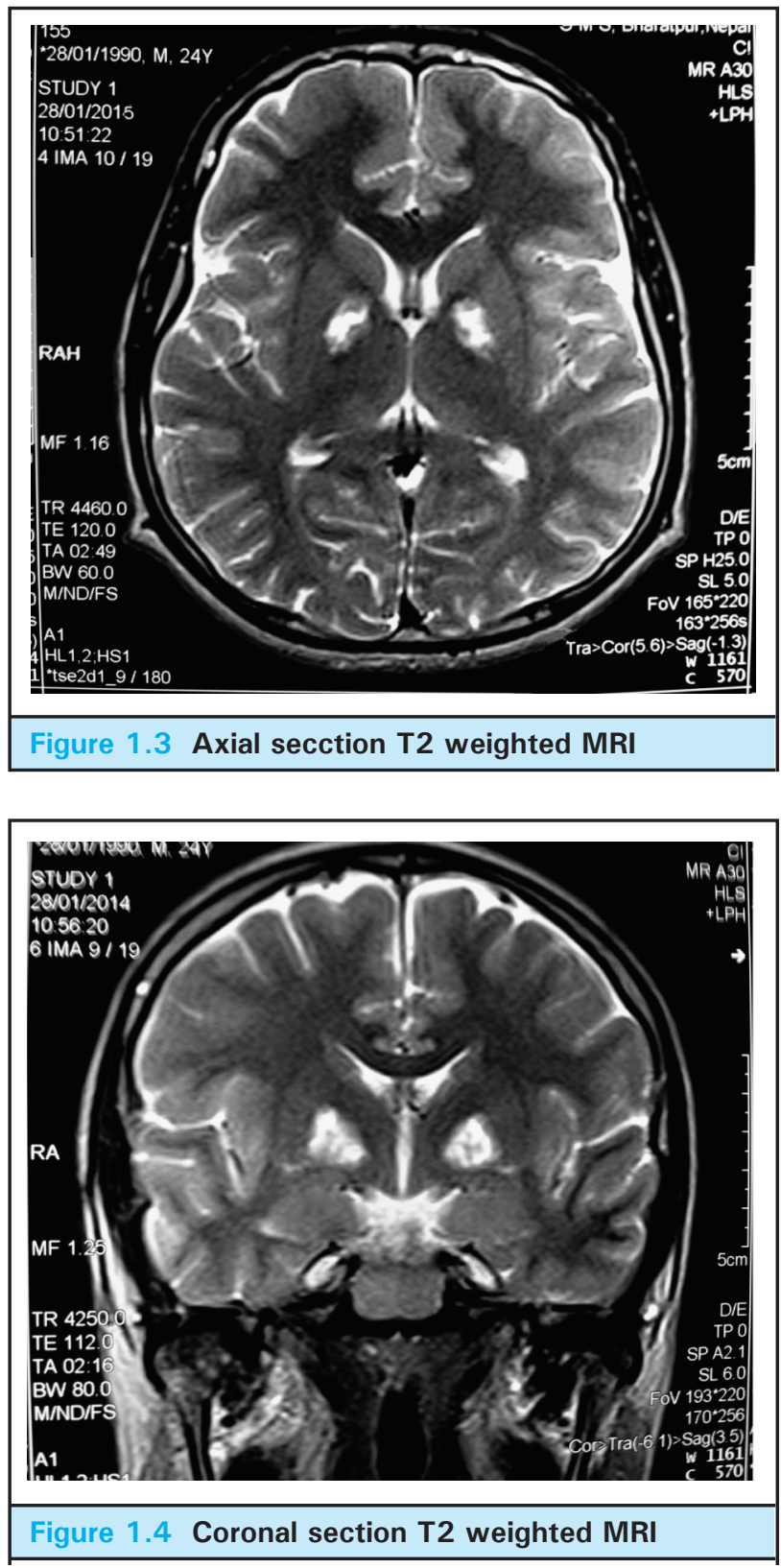


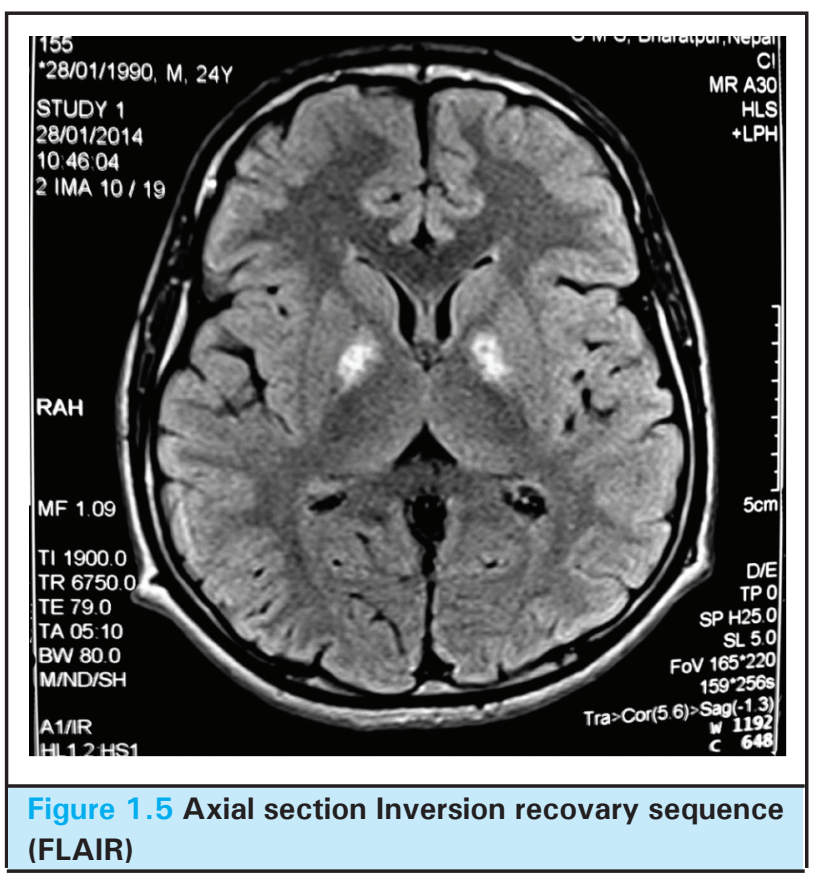

Diffuse hypoxic-ischaemic encephalopathy usually develops only in cases of acute and severe $\mathrm{CO}$ poisoning or prolonged exposure. This usually presents as diffuse increased signal in the cortex on T2-weighted or FLAIR images. Focal cortical injury is considerably less common, usually affecting the temporal lobe or hippocampus. ${ }^{5}$

Diffuse brain atrophy and cerebral white matter demyelination are late manifestations of $\mathrm{CO}$ poisoning. ${ }^{9,10}$ The most common sites of involvement are the periventricular white matter and centrum semiovale; the subcortical white matter, corpus callosum and both the internal and external capsules are involved in cases of severe poisoning. ${ }^{11}$

Globus pallidus lesions in many cases do not correlate directly to clinical status and outcome; however, the presence of diffuse white matter disease is a more reliable index of both. ${ }^{3}$

In conclusion, correlation of typical imaging features with clinical history and laboratory data is of utmost importance in arriving at the correct diagnosis. Conventional MRI still proves to be an invaluable asset in quantifying the damage to the $\mathrm{CO}$ poisoned brain although early changes may be well discerned with newer techniques.

\section{ACKNOWLEDGEMENT}

The authors have not received any funding or benefits from industry or elsewhere to conduct this study.

\section{REFERENCES}

1. 1.T. Beppu.The Role of MRI maging in Assessment of Brain Damage from Carbon Monoxide Poisoning: A Review of the Literature. AJNR Am J Neuroradiol. 2014 Apr.35:625-31.

2. 2. Omaye ST. Metabolic modulation of carbon monoxide toxicity. Toxicology 2002; 180:139-50

3. 3. Prockop LD, Naidu KA. Brain CT and MRI findings after carbon monoxide toxicity. J Neuroimaging. 1999 Jul;9 (3):175-81.

4. 4. Hegde A N, Mohan S, Lath N, Lim C C T. Differential Diagnosis for Bilateral Abnormalities of the Basal Ganglia and Thalamus. RSNA 2011;31(1):5-30

5. 5. Puay Joo Lim1, Sumer Nrupendra Shikhare, Wilfred CG Peh,. Clinics in diagnostic imaging. Singapore Med J 2014; 55(8): 405-10.

6. 6. O'Donnell P, Buxton PJ, Pitkin A, Jarvis LJ. The magnetic resonance imaging appearances of the brain in acute carbon monoxide poisoning. Clin Radiol. 2000 Apr;55(4):273-80
7. 7. Lo CP, Chen SY, Lee KW, Chen WL, Chen CY, Hsueh CJ, Huang GS, Lo CP, Chen SY, Lee KW. Brain Injury After Acute Carbon Monoxide Poisoning: Early and Late Complications. AJR.October 2007:189.

8. 8. Sener RN. Acute Carbon Monoxide Poisoning:Diffusion MR Imaging Findings. AJNR Am J Neuroradiol .August 2003;24:1475-7.

9. 9. Lo CP, Chen SY, Lee KW, et al. Brain injury after acute carbon monoxide poisoning: early and late complications. AJR Am J Roentgenol. 2007; 189: 205-11.

10. 10. O'Donnell P, Buxton PJ, Pitkin A, Jarvis LJ. The magnetic resonance imaging appearances of the brain in acute carbon monoxide poisoning. Clin Radiol 2000; 55:273-80.

11. 11.Chang KH, Han MH, Kim HS, Wie BA, Han MC. Delayed encephalopathy after carbon monoxide intoxication: MR imaging features and distribution of cerebral white matter lesions. Radiology 1992; 184:117-22. 